\title{
Bioefficacy of Lemongrass and Tea Tree Essential Oils Against House Fly, Musca domestica
}

\author{
Jyoti M. Chintalchere ${ }^{1} \cdot$ Mudasir A. Dar $^{1} \cdot$ Kishor D. Raut $^{1} \cdot$ Radhakrishna S. Pandit $^{1}$
}

Received: 13 December 2019/Revised: 3 November 2020/Accepted: 17 December 2020/Published online: 18 February 2021

(C) The National Academy of Sciences, India 2021

\begin{abstract}
The management of house fly, Musca domestica has become immensely important to prevent epidemics of many detrimental diseases. In view of this objective, the present study demonstrates the efficacy of lemongrass (LG) and tea tree essential oils (TTEOs) against $M$. domestica. The TTEO proved to be more lethal against larvae and adults of $M$. domestica depicting an $\mathrm{LC}_{50}$ at $14.88 \mathrm{mg} / \mathrm{dm}^{3}$ which was $17.19 \mathrm{mg} / \mathrm{dm}^{3}$ for LGEO. In contrast, pupicidal
\end{abstract}

Significance statement The housefly, Musca domestica is a menace for the modern civilization due to its role in transmission of fatal diseases. The present manuscript highlights lemongrass and tea tree essential oils as potential biopesticides against $M$. domestica.

Supplementary Information The online version of this article ( https://doi.org/10.1007/s40011-020-01220-z) contains supplementary material, which is available to authorized users.

Mudasir A. Dar

mudasir.dar@unipune.ac.in

$\triangle$ Radhakrishna S. Pandit

panditrao499@gmail.com

Jyoti M. Chintalchere

chintalcherejyoti@gmail.com

Kishor D. Raut

kishor5raut@rediffmail.com

1 Department of Zoology, Savitribai Phule Pune University, Pune, Maharashtra 411007, India effect of LGEO was much higher $\left(\mathrm{LD}_{50}, 14.49 \mu \mathrm{l} / 0.25 \mathrm{~L}\right)$ as compared to TTEO. The LGEO drastically reduced the total body sugar, glycogen and protein contents by 3.29 , 2.95 and 7.56 fold, respectively, contrasting with high influence of TTEO on lipid content of the late 3rd instar larvae. A considerable reduction in gut enzymes secretion was observed due to treatment of EOs thereby altering gut physiology of the insect. Moreover, significant inhibition of acetylcholine esterase (AchE) was also observed with LGEO at $\mathrm{LC}_{50}$ concentration $(5.33 \mathrm{mg} / \mathrm{ml})$ inhibiting insect neurotransmission. The gas chromatography-mass spectrometric (GC-MS) analysis of the LGEO showed 12 major compounds dominated by Citral whereas TTEO contained only 5 major compounds. Further analysis by field emission scanning electron microscopy (FESEM) revealed distortion and shrinkage of larval bodies caused by the treatment of EOs. These overall observations brand LG and TT-EOs as potential organic-insecticides against M. domestica. 


\section{Graphic Abstract}
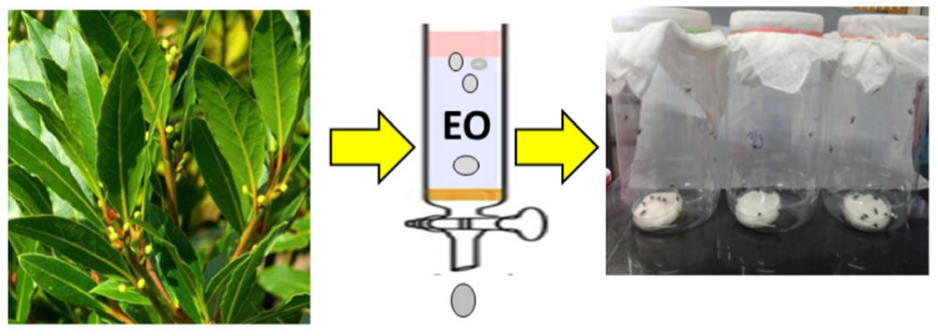

0
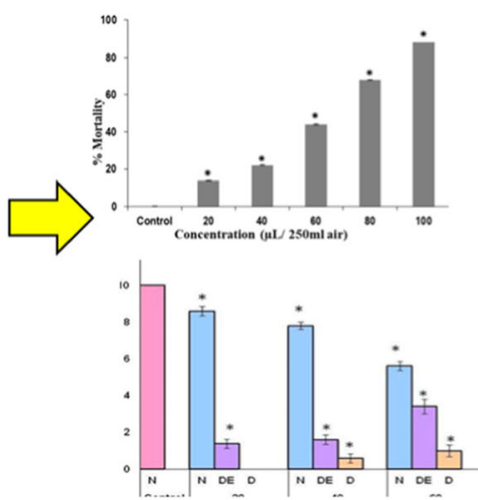
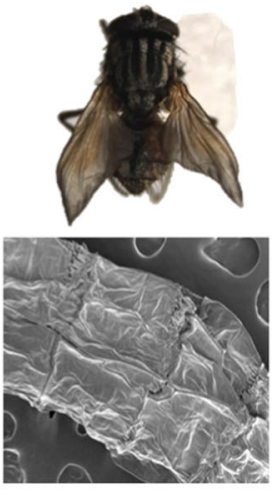

Keywords Musca domestica - Essential oils · Botanicals · Vector-borne diseases · Mortality · GC-MS analysis

\section{Introduction}

The holometabolous insect, Musca domestica also called house fly plays its part as a vector of many fatal diseases. It has become a worldwide problem for transmission of pathogens such as protozoan cysts, helminth parasites, enteropathogenic bacteria, Turkey coronavirus, enterovirus as well as avian flu [1]. It causes heavy damage to livestock, poultry and humans. It has been very instrumental for the epidemics of dysentery, diphtheria, typhoid, leprosy in humans, whereas fowl cholera and anthrax diseases of poultry and livestock [2]. The frequent movement of flies between animals and rotten food makes them ideal porters for disease causing pathogens. Therefore, the population control of this pest below threshold levels becomes immensely important from the public health viewpoint and has attracted attention of the scientific community worldwide. During the last century chemical control was the only potential option for managing this insect, but in the present era of advanced technologies many prospective alternatives, such as cultural tactics and biological agents, are routinely used for controlling this pest. Moreover, house flies are reported to show resistance to chemical agents such as organochlorines, organophosphates, pyrethroids, etc. [3]. Furthermore, synthetic pesticides are also wellknown to harm non-target organisms, cause bioaccumulation in trophic levels, ecological imbalances and environmental pollution. Thus, there is a dire need to prospect for new, promising and sustainable biological agents that could be potential tools for managing the housefly populations below threshold levels. Prospectively, there are renewed efforts to develop plant-based formulations which could be considered as highly effective, eco-friendly, cheap, biodegradable and safe for humankind as well as the environment. According to Isman, favorable eco-toxicological properties of botanical pesticides make them potentially suitable for use in integrated pest management (IPM) programs [4]. Consequently, essential oils (EO) extracted from plants are reviewed as potential plant-based organicagents due to their inherent valuable properties.

Since EOs are mixtures of organic compounds that can accomplish multiple functions such as protein denaturation, enzymatic inhibition and membrane disintegration in animals [5]. Some compounds may act as insect growth regulators (IGR) affecting the neuromuscular system of pests and mimic the symptoms of organophosphates. While others absorb through the cuticle and function as fumigants causing respiratory damage [6]. Since every pesticide has its pros and cons but the specialty of plant-based formulations being species-specific and biodegradable makes them an ideal choice for future pest management practices. The EOs from LG and TT are known to be stress relievers bearing many medicinal properties for humans. However, their valorization for pest management in general and house flies in particular has remained to be explored. Thus, in the present study, we investigated the effects of LG and TTEOs against the menacing house fly, $M$. domestica. The efficacy of EOs were tested on different life stages of the model insect by using various biochemical techniques while the morphological alterations imposed by EO treatment were also determined using FESEM. Moreover, attempts were made to explore the composition of EOs under consideration in order to confirm the active ingredients responsible for insecticidal properties. 

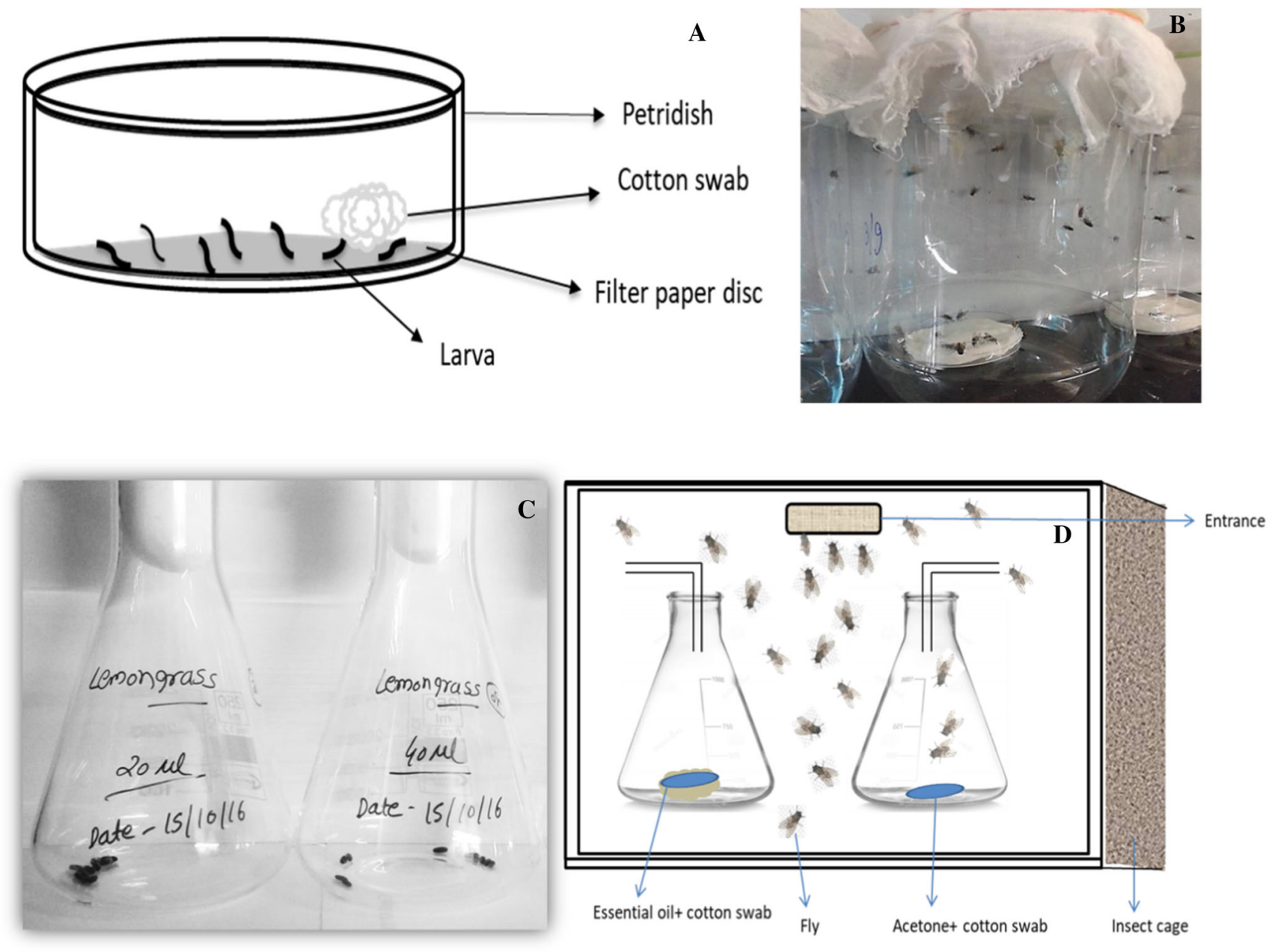

Fig. 1 An outline of the different bioassays carried out in the present study. a set up for larvicidal assay, b Adulticidal assay carried out in plastic jars containing petri dish sprayed with milk solution as food, $\mathbf{c}$ Pupicidal assay and $\mathbf{d}$ Attractant/repellent assay

\section{Material and Methods}

\section{Chemicals and Reagents}

The EOs of lemongrass (Cymbopogon citratus) and tea tree (Melaleuca alternifolia) used in the study were procured from Sigma Aldrich, (Millipore Sigma, USA). The EOs were diluted in acetone solution (Merck, corporate, USA) to prepare the doses for different assays or experiments. All other reagents and chemicals used in the study were of analytical or molecular grade unless otherwise mentioned.

\section{Insect Rearing}

The culture of housefly, M. domestica procured from the national chemical laboratory (NCL), Pune (M.S.), India, was maintained at $28 \pm 2{ }^{\circ} \mathrm{C}$ and $60-70 \%$ R.H. for several generations in plastic jars of $35 \times 15 \mathrm{~cm}$ dimension as described previously [7]. The jars were covered with muslin cloth to prevent the flies from escape. The adult flies were fed ad libitum on $10 \%$ milk solution (w/v) offered through a cotton swab which served dual purpose for food as well as substratum for oviposition. The food was changed regularly to prevent the contamination by microorganisms. The rod-shaped eggs laid in batches were whitish in color and approximately $1.2 \mathrm{~mm}$ in size (Fig. 1a). The eggs after oviposition were stored in different sets of jars for hatching. The newly hatched larvae, creamy whitish in color (Fig. 1b) were fed on milk solution. The first to third larval instars were identified on the basis of size of the larva and time after hatching by following the descriptions of Hussein and Capinera [8]. The collected pupae were kept separate for emergence into adult. Finally, the freshly emerged adults were also used for various bioassays.

\section{Larvicidal Assay}

The larvicidal assays were carried out by using the residual film method [7] with slight modifications. Briefly, the 
effect of different concentrations of tested oils, were checked on 3rd instar larvae $(n=10)$ to determine the $\mathrm{LC}_{50}$ and $\mathrm{LC}_{90}$ concentrations. To achieve this, $1 \mathrm{~mL}$ of the acetone solution containing desired concentration of EO, were spread uniformly on filter paper disc laid inside the glass petri dish of 90-mm-diameter (Fig. 1a). The petri dishes were left open till solvent evaporation followed by inoculation of larvae $(n \geq 10)$. These tests were carried out under strictly maintained rearing conditions for $24 \mathrm{~h}$. However, in control experiments only solvent, i.e., acetone in place of EO was sprayed following a similar procedure to that in test sets. The larvae were fed on cotton swab soaked in milk solution. The actual dose of EO present in $1 \mathrm{~mL}$ mixture was calculated by using the following formula considering the area of petri dish as $63.58 \mathrm{~cm}^{2}$.

$$
\text { Dose } / \mathrm{cm}^{2}=\text { concentration present in } 1 \mathrm{~mL} \text { solution/ }
$$$$
\text { area of petri dish }
$$

The larval mortality was determined after $24 \mathrm{~h}$ of exposure with $\mathrm{EO}$ to calculate the mean mortality for $\mathrm{LC}_{50}$, and $\mathrm{LC}_{90}$ values using probit analysis [9]. In case of LGEO, the assays were repeated 7 times while the test with TT was repeated 10 times to get the fair results for larval mortality caused by the tested compounds.

\section{Adulticidal Bioassay}

The adulticidal assay on $M$. domestica was carried out according to the method described previously [7] with minor changes. The bioassays were designed such that the flies would have a maximum probability of exposure to the tested concentration of EOs. The adult houseflies $(n=10)$ were transferred to a plastic jar of $1.2 \mathrm{dm}^{3}$ having a cotton yarn attached internally to the cap (Fig. 1b). The cotton yarn was sprayed with different concentrations of EO in the range of $10-100 \mathrm{mg} / \mathrm{dm}^{3}$ which was dissolved in $10 \mu \mathrm{L}$ acetone. To avoid direct contact of flies with EO, the cotton yarn was covered with a thin muslin cloth. In case of control set, the cotton yarn enclosed in muslin cloth contained only $10 \mu \mathrm{L}$ of acetone. The experiments were replicated 10 times at $28 \pm 2{ }^{\circ} \mathrm{C}$ for $30 \mathrm{~min}$ to calculate the mortality rate caused by $\mathrm{EO}$ treatment.

\section{Attractant/Repellant Bioassay}

The attractant/repellent assays were carried out by double choice method [7] where 20 individuals of newly emerged adult flies were released in a cage containing 2 conical flasks. One flask contained $0.1 \%$ test oil in $5 \mathrm{~mL}(\mathrm{v} / \mathrm{v})$ of milk, while the other contained acetone as solvent with $5 \mathrm{~mL}$ of milk to serve as a control. The EO containing conical flask was fitted with a funnel $(10 \mathrm{~cm}$ diameter $)$ outwards to avoid the escape of the flies (Fig. 1d). The number of flies attracted toward test oils, and solvent only in control flask were recorded after $24 \mathrm{~h}$ of treatment, and the percent $(\%)$ repellency was determined by using the formula;

$\%$ Repellency $=[100(C-T) / C]$

where $C$ is the number of flies trapped in control flask, $T$ denotes the number of flies trapped in treated flask.

\section{Pupicidal Bioassays}

To determine the effect of EO on pupal emergence into adults, two types of assays such as volatile and contact toxicity protocols as described by Kumar et al. [10] were followed. Twenty pupae (3 days old) were placed in $250 \mathrm{~mL}$ conical flasks (Fig. 1c) containing respective concentrations ranging from $20 \mu \mathrm{L}$ to $100 \mu \mathrm{L} / 0.25 \mathrm{~L}$ of air. The observations were recorded up to 6 days post exposure at $28 \pm 2{ }^{\circ} \mathrm{C}$ and $\mathrm{RH} 65 \pm 5 \%$, and the percent $(\%)$ reduction of emergence into adults or inhibition rate (\%IR) was calculated by following the formula;

\%Inhibition rate $=\mathrm{Cn}-\mathrm{Tn} / \mathrm{Cn} \times 100$

where $\mathrm{Cn}$ is number of emerged insects in control set, and Tn corresponds to the number of emerged adults after EO treatment.

\section{Effect of EOs on Sugar, Glycogen and Lipid Contents}

To determine the effect caused by EO treatment on the larval body, 3rd instar larvae $(n=10)$ were exposed to $\mathrm{LC}_{50}$ concentrations of test oils for $24 \mathrm{~h}$. After treatment, the larvae were sacrificed to estimate the biochemical components like total sugar, glycogen and lipid contents. The body contents were homogenized in $0.2 \mathrm{~mL}$ Sodium sulfate solution (w/v) followed by addition of $0.8 \mathrm{~mL}$ methanol in chloroform $(1: 1, \mathrm{v} / \mathrm{v})$. The homogenized mixture was centrifuged at $3000 \mathrm{rpm}$ for $2 \mathrm{~min}$, and the supernatant was harvested for glycogen estimation by Anthrone method [11]. The pellet obtained was further suspended in $3 \mathrm{~mL}$ of $\mathrm{dH}_{2} \mathrm{O}$ and centrifuged at $3000 \mathrm{rpm}$ for $2 \mathrm{~min}$ to observe the formation of 2 layers. The upper aqueous layer was used for sugar analysis by the method of Van Handel and Day [11] while the bottom layer chiefly formed of chloroform containing lipids was mixed with $0.2 \mathrm{~mL} \mathrm{H}_{2} \mathrm{SO}_{4}$ then heated for $10 \mathrm{~min}$ at $90{ }^{\circ} \mathrm{C}$. The color change caused by the addition of $5 \mathrm{~mL}$ Vanillin reagent was measured at $625 \mathrm{~nm}$ spectrophotometrically (Carry 60, Agilent technologies, USA). For sugar and glycogen content, glucose was used as standard whereas Soybean oil was used in case of lipids. The total body proteins were 
determined by Bradford assay [12] using BSA as standard after homogenization of the larval body in $1 \mathrm{~mL}$ of lysis buffer (0.1 M PMSF, $0.1 \mathrm{M}$ tris Cl, $1 \mathrm{M}$ EDTA, $1 \mathrm{M} \mathrm{NaCl}$, 1 M DTT, 20\% glycerol) followed by centrifugation at $5000 \mathrm{rpm}$ for $5 \mathrm{~min}$. The biochemical components under consideration were determined in terms of micrograms $(\mu \mathrm{g}) / \mathrm{larva}$, derived from the standards. These tests were repeated at least 5 times to get the constant results.

\section{Effect of Essential Oil on Gut Enzymes}

To check the effect of EO treatment on gut enzymes, gut regions of control and treated larvae were homogenized in PBS (pH 7.4) then centrifuged as described above in protein assay. The supernatant obtained was subjected to different enzyme assays such as $\alpha$-amylase, $\alpha$ - as well as $\beta$ glucosidase activities. The $\alpha$-amylase activity was carried out by dinitrosalicylic acid (DNSA) procedure [13]. Briefly, $20 \mu \mathrm{L}$ of the enzyme extract, in $50 \mu \mathrm{L}$ of universal buffer ( $\mathrm{pH}$ 7.4) was mixed with $25 \mu \mathrm{L}$ of soluble starch $(1 \%, w / v)$. The reaction mixture was incubated at $35^{\circ} \mathrm{C}$ for $30 \mathrm{~min}$ followed by the addition of $85 \mu \mathrm{L}$ DNSA reagent and heated in a boiling water bath for $10 \mathrm{~min}$ to terminate the reaction. After cooling the reaction mixtures on ice, absorbances were measured spectrophotometrically at $540 \mathrm{~nm}$.

The $\alpha$ - and $\beta$-glucosidase activities were determined as per the method described previously [7] using p-nitrophenol as standard. The reaction mixture contained $50 \mu \mathrm{L}$ of enzyme sample with $75 \mu \mathrm{L}$ of $5 \mathrm{mM} p$-N- $\alpha$-D-glucopyranoside or $p$-nitrophenyl- $\beta$-d-glucopyranoside (as substrates) for $\alpha$ - and $\beta$ glucosidase, respectively. To the reaction mixture, $125 \mu \mathrm{L}$ of universal buffer $(100 \mathrm{~mm}, \mathrm{pH}-$ 7.0) was added, followed by incubation for $30 \mathrm{~min}$ at $25{ }^{\circ} \mathrm{C}$. Reactions were stopped by $2 \mathrm{~mL}$ of $0.1 \mathrm{M}$ Sodium carbonate or $\mathrm{NaOH}$, and absorbances were read spectrophotometrically at $405 \mathrm{~nm}$. The enzyme activity is defined as the amount of enzyme required to liberate $1 \mathrm{mg}$ maltose under standard assay conditions.

\section{Acetylcholinesterase (AChE) Activity}

Acetylcholinesterase (AChE) activity was assayed by using Ellman's reagent, DTNB [14] at $412 \mathrm{~nm}$. The reaction mixture composed of $10 \mu \mathrm{L}$ enzyme sample with $180 \mu \mathrm{L}$

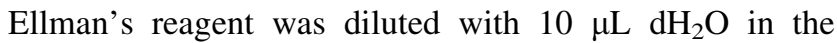
presence of $20 \mu \mathrm{L}$ Acetylthiocholine $(20 \mathrm{mM})$ as substrate. The enzyme activity was measured in $\mathrm{U} / \mathrm{mg}$ of extract.

\section{Gas Chromatography- Mass Spectrometric (GC- MS) Analysis of EOs}

To check the chemical composition of the tested EOs, we employed GC-MS approach using GC-MS-TQ8030 apparatus, equipped with RTX 5MS column at an ionizing voltage of $70 \mathrm{eV}$. The mass spectra obtained were compared with the relevant compounds in NIST11 library of GC-MS data system as well as already reported literature. The GC-MS of Lemongrass EO analysis was carried out by the method of Mirghani and coworkers [15]. The GC consisted of primary heating from 50 to $150{ }^{\circ} \mathrm{C}$ at $6{ }^{\circ} \mathrm{C} /$ min followed by an increment from 10 to $250^{\circ} \mathrm{C}$ which was maintained for $10 \mathrm{~min}$. Injector temperature was maintained at $220^{\circ} \mathrm{C}$, and the MS transfer line temperature was set at $290{ }^{\circ} \mathrm{C}$. Helium was used as a carrier gas at a flow rate of $1 \mathrm{~mL} / \mathrm{min}$ and a split ratio of 1:30. However, for GC-MS analysis of TTEO, slight modifications were made by changing the column temperature from 60 to $240{ }^{\circ} \mathrm{C}$ with an increase of $3{ }^{\circ} \mathrm{C} / \mathrm{min}$, maintained for 35 min.

\section{Field Emission Scanning Electron Microscopic (FESEM) Analysis of Treated Larvae}

To study the effect of EOs on insect morphology, 10 larvae were exposed to $\mathrm{LC}_{50}$ concentrations for $24 \mathrm{~h}$. After treatment, the larvae were prepared for FESEM analysis to observe the changes in integument and surface structures. The morphology of the treated and control larvae were observed in an electronic microscope (FESEM 450, FEI Nova Nano, USA) complemented with EDS system at a voltage of $3 \mathrm{kV}$. For FESEM visualization, the samples were primarily fixed in $2.5 \%$ glutaraldehyde for $12 \mathrm{~h}$, then washed with distilled water for $20 \mathrm{~min}$ followed by a secondary fixation with $4 \%$ Osmium tetroxide. The samples were further dehydrated with different ethanolic grades $(25,50,75,90$ and $100 \%$ ethanol) each for $10 \mathrm{~min}$ at RT. Finally, the samples were subjected to critical point drying (CPD) and mounted on carbon tape followed by sputter coating with $100 \AA$ gold.

\section{Statistical Analysis}

All the bioassays were independently replicated five or more times unless mentioned. The data obtained was statistically analyzed in SPSS software version 22 (IBM SPSS, NY, USA), and the obtained results are reported as mean \pm standard error mean (SEM) of five or more replicates. One-way analysis of variance (ANOVA) was carried out by using Tukey's test $(p<0.001)$. The $\mathrm{LC}_{50}$ and $\mathrm{LC}_{90}$ values with their $95 \%$ confidence limits were 
Table 1 Larvicidal and adulticidal activities of tested essential oils against $M$. domestica after $24 \mathrm{~h}$ of treatment depicting $\mathrm{LC}_{50}$ and $\mathrm{LC}_{90}$ concentrations

\begin{tabular}{|c|c|c|c|c|c|c|c|}
\hline \multirow[t]{2}{*}{ Essential Oil } & \multirow[t]{2}{*}{ Insect stage } & \multirow[t]{2}{*}{$\mathrm{LC}_{50}(\mathrm{mg} / \mathrm{ml})^{\#}\left(\mathrm{mg} / \mathrm{dm}^{3}\right)^{\# \#}$} & \multicolumn{2}{|c|}{$\begin{array}{l}\text { 95\%Confidential limit } \\
\left(\mathrm{LC}_{50}\right)\end{array}$} & \multirow[t]{2}{*}{ Regression Equation } & \multirow[t]{2}{*}{$\mathrm{LC}_{90}(\mathrm{mg} / \mathrm{ml})^{\#}\left(\mathrm{mg} / \mathrm{dm}^{3}\right)^{\# \#}$} & \multirow[t]{2}{*}{ Chi square } \\
\hline & & & LCL & UCL & & & \\
\hline \multirow[t]{2}{*}{ Tea tree } & Larvae & 4.94 & 3.98 & 5.84 & $y=0.31-1.53 x$ & 9.08 & $17.00 *(5)$ \\
\hline & Adult & 14.88 & 6.65 & 25.01 & $y=0.41-608 x$ & 46.27 & $16.67 *(5)$ \\
\hline \multirow[t]{2}{*}{ Lemongrass } & Larvae & 5.33 & 2.74 & 7.41 & $y=0.209-1.114 x$ & 11.46 & $41.31 *(5)$ \\
\hline & Adult & 19.17 & 3.41 & 31.69 & $y=0.24-0.465 x$ & 72.05 & $11.87 *(5)$ \\
\hline
\end{tabular}

$\mathrm{LC}_{50}$ and $\mathrm{LC}_{90}$ are lethal concentration at which $50 \%$ and $90 \%$ population died, respectively. \# Unit representing the larval mortality; \#\# unit used for adulticidal activity

*Significant at $p<0.001$. Each value represents mean of five replicates
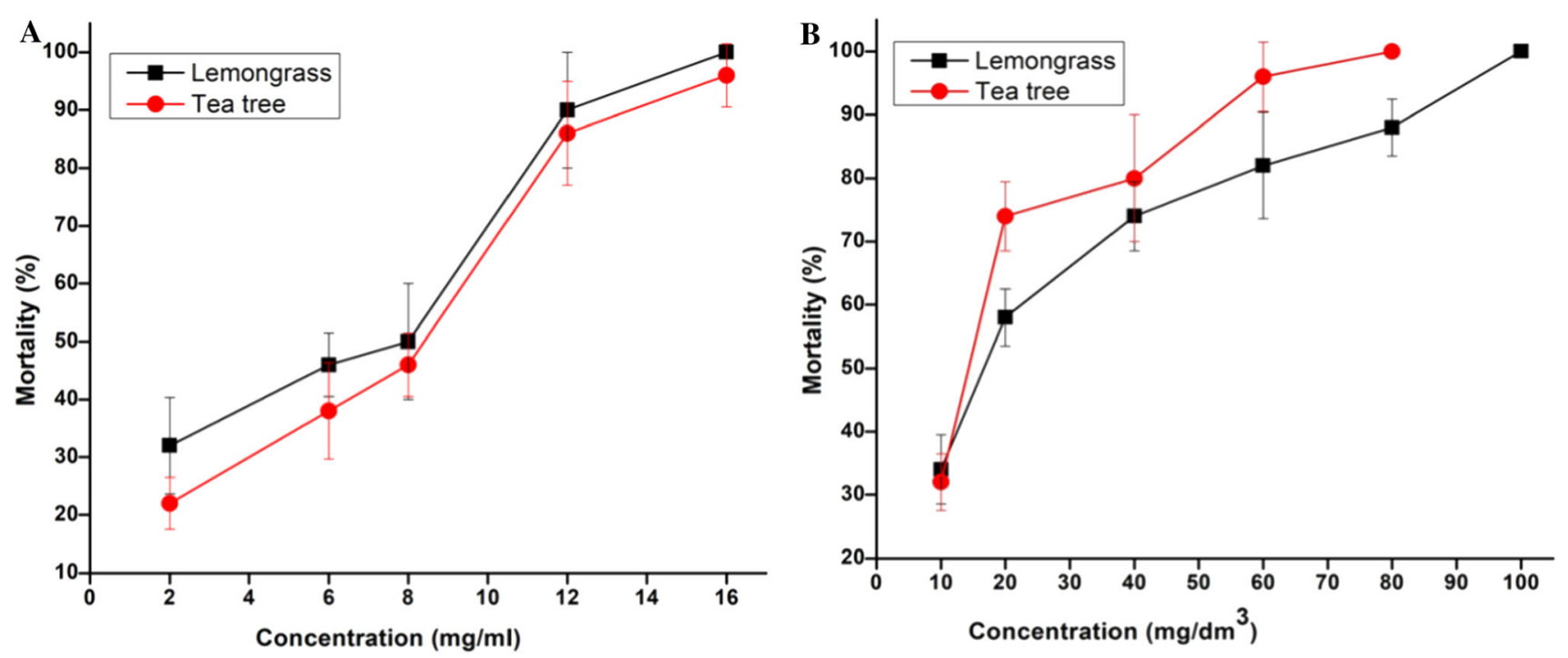

Fig. 2 Larvicidal (a) and adulticidal (b) activities of tested essential oils on M. domestica larvae. Each value represents mean of five or more replicates

determined by probit analysis, which helped to analyze the dose-mortality response [9].

\section{Results and Discussion}

\section{Larvicidal Activity}

Among the EOs tested against the larvae of $M$. domestica, it was observed that TTEO proved to be more effective as compared to LGEO as depicted by the lower concentration required for $50 \%$ mortality of the larvae (Table 1). The TTEO showed higher larvicidal activity at $\mathrm{LC}_{50} 4.94 \mathrm{mg} /$ $\mathrm{mL}$ (actual dose was $0.0776 \mu \mathrm{g} / \mathrm{cm}^{2}$ ) which was very low and statistically significant $(p<0.001$ level $)$ than LG essential oil requiring $5.33 \mathrm{mg} / \mathrm{mL}$ (actual dose was $0.0838 \mu \mathrm{g} / \mathrm{cm}^{2}$ ) to kill $50 \%$ of pest populations. Though it is not surprising to observe the increased mortality rate with increased concentrations of EO but the time required by TTEO to achieve $\mathrm{LC}_{50}$ which was only $24 \mathrm{~h}$ is quite fascinating (Fig. 2a). It can further elucidate that shortterm exposure of larvae to lethal doses can markedly increase their mortality over time, and thus reduce the population levels below threshold. Our observations were in line with Shalaby and coworkers who reported that lemon oil shows higher larvicidal activity [16]. Similarly Bosly, [17] stated that EOs from Mentha piperita and Lavandula angustifolia caused mortality and prolonged larval stages in $M$. domestica thereby show a potential insecticidal effect.

\section{Adulticidal Assay}

Since both the EOs exhibited adulticidal activities but the activity depicted by TT compound was significant with $\mathrm{LC}_{50}$ and $\mathrm{LC}_{90}$ concentrations of $14.88 \mathrm{mg} / \mathrm{dm}^{3}$ and $46.27 \mathrm{mg} / \mathrm{dm}^{3}$, respectively (Table 1 ). However, LGEO showed $\mathrm{LC}_{50}$ at $19.17 \mathrm{mg} / \mathrm{dm}^{3}$ and $\mathrm{LC}_{90}$ with $72.05 \mathrm{mg} /$ 
Table 2 Attraction/ repellency potential of essential oils toward M. domestica

\begin{tabular}{llcll}
\hline Sr. no. & Essential oil & Mean no. of flies attracted in control & Mean no. of flies attracted in test & $\%$ Repellency \\
\hline 1 & Lemongrass & $8.2 \pm 0.37$ & $1.6 \pm 0.4$ & 67.34 \\
2 & Tea tree & $10.8 \pm 0.58$ & $1.4 \pm 0.24$ & 77.04 \\
\hline
\end{tabular}

$\mathrm{dm}^{3}$, showing $100 \%$ mortality at concentration $100 \mathrm{mg} /$ $\mathrm{dm}^{3}$ which was higher than TTEO $\left(80 \mathrm{mg} / \mathrm{dm}^{3}\right)$ (Fig. 2b). The Chi square values and $95 \%$ confidence limits indicated that the results obtained were statistically significant at $p<0.001$. A similar trend like larvicidal activity was observed in case of adulticidal activity; with increased dose the percent $(\%)$ mortality also increased showing positive correlation with the bioefficacy of the tested compounds. Similar inferences have been reported by Shalaby and coworkers [16] while testing the effect of peel oil from grapefruit on $M$. domestica.

\section{Attractant/Repellant Bioassay}

In this assay, TTEO showed $77.04 \%$ repellency which was slightly higher than the repellency potential of LG, (i.e., $67.34 \%$ repellency) at a concentration of $0.1 \%$ (Table 2). Recently, the repellent activity of Cymbopogon citratus (lemongrass) EO against mosquitoes has been examined by Oyedele et al. [18]. Jayasinghe and Fujimoto, [19] stated that repellent potential to $C$. citrates is majorly imparted by its dominant compound geraniol while testing them against Sitotroga cerealella and Tribolium castaneum. However, Kumar et al. [10] have revealed that some monoterpene aldehydes such as Linalool, linalyl acetate, Citral a and

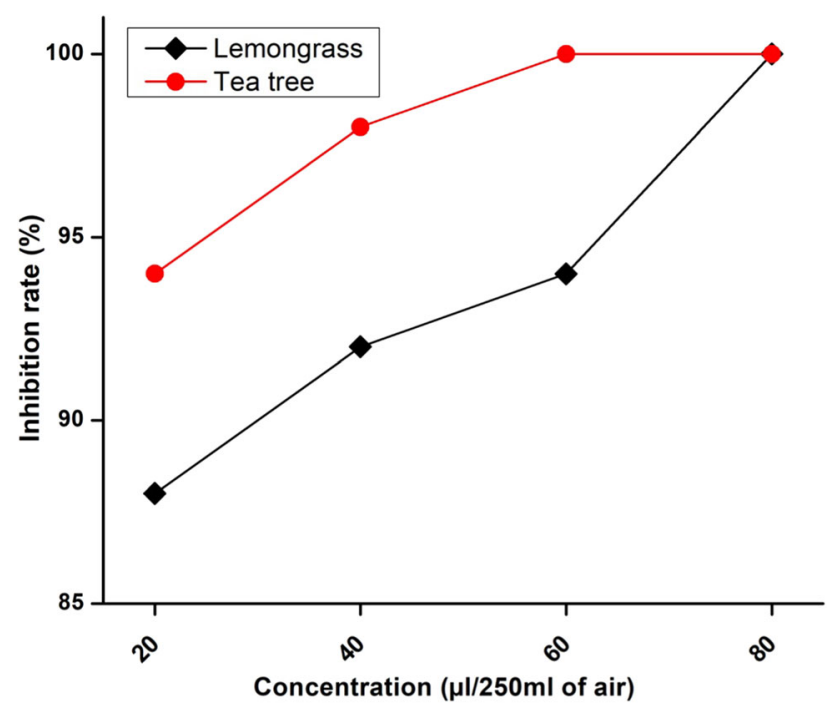

Fig. 3 Percentage inhibition on pupal emergence due to Lemongrass (a), and Tea tree (b) essential oils against $M$. domestica
Citral $\mathrm{b}$ are the main factors responsible for repellent activity of $C$. citratus.

\section{Pupicidal Bioassay}

The literature related to deformity of insects by EO is scanty, and the underlying molecular mechanism remains unclear. The pupicidal assay carried out by two different methods proved that contact toxicity also known as topical method is more effective than fumigation approach for housefly control with LG and TTEOs. In fumigation assay, the lethal dose evaluated by probit analysis showed significant activity with LGEO which exhibited $\mathrm{LD}_{50}$ and $\mathrm{LD}_{90}$ values at $14.49 \mu \mathrm{L} / 0.25 \mathrm{~L}$ and $37.45 \mu \mathrm{L} / 0.25 \mathrm{~L}$, respectively. The TTEO showed $\mathrm{LD}_{50}$ and $\mathrm{LD}_{90}$ concentrations as $29.68 \mu \mathrm{L} / 0.25 \mathrm{~L}$ and $59.51 \mu \mathrm{L} / 0.25 \mathrm{~L}$. In fumigation assay LGEO was found to be more toxic against pupae than TTEO (Fig. 3). In case of contact toxicity method none of the flies emerged into normal adults ensuring either $100 \%$ mortality of the pupae or deformities after emergence due to EO treatment. The LGEO showed complete (100\%) inhibition of pupae at a concentration of $100 \mu \mathrm{L} / 0.25 \mathrm{~L}$ of air displaying more toxic nature, whereas the concentration of TTEO required for $100 \%$ inhibition was found to be $80 \mu \mathrm{L} / 0.25 \mathrm{~L}$ of air displaying more toxic nature. With increased doses in fumigation assay the inhibition rate (IR) also increased in both the oils showing maximum deformities in adults. The higher proficiency (100\% inhibition) in the contact toxicity method for pupicidal effect could be attributed to the collapse of the insect neural system, therefore causing instant and complete knockdown of the flies which was also reported by Kumar et al. [10] while testing the effect of crude oils from $E$. globulus and M. piperita on M. domestica.

Further, it was observed that LGEO is more effective on pupae as compared to TTEO causing adult deformation, shrinkage of wings and even producing pupal-adult intermediates (Fig. 4). However, such effects were also observed by Dimetry et al. [20] while examination of volatile oil from $P$. nigra on 3rd instar larvae of $M$. domestica. Some authors have observed that treatment of T. vulgaris and Z. officinale EOs on C. albiceps produces larval-pupal or pupal-adult intermediates with crumpled wings. The effect of EO from LG and TT are more 
Fig. 4 Inhibition of pupal emergence into adults

(a) caused by the essential oil treatment; (b) shows the deformation of adult undergoing emergence
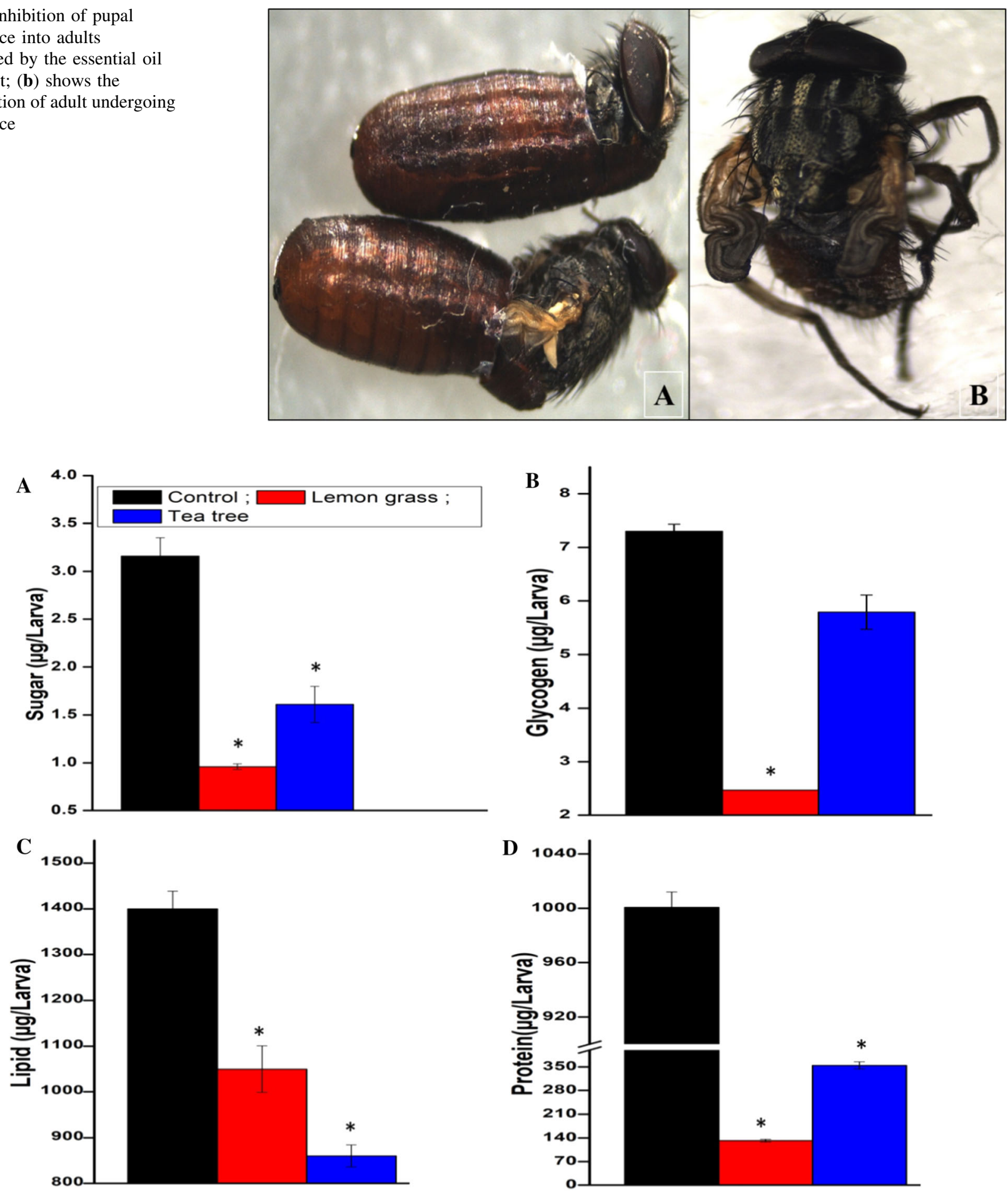

Fig. 5 Effect of EO treatment on the biochemical reserves of house fly, M. domestica. A; total body sugar, B; total body glycogen, C; total body lipid content, and D; total body protein. Data analyzed by One-

promising than $C$. aurantifolia peels or Citrus sinensis which show only $70 \%$ fumigant effectiveness against houseflies [21]. The difference in efficacy between contact toxicity and fumigation assays may be due to the different

way ANOVA, followed by Tukey's test and significance at $* p<0.001$ compared with control

percentage contributions of chemical components in two phases of oils. Further in the fumigation assay it was observed that $\%$ inhibition of house flies is dose dependent because the increased dose of EOs causes increase in \% IR 
of pupae and increased chances of deformities in adult flies.

\section{Effect of EO on Biochemical Components of Larval Body}

Since the nutritional reserves like lipids, sugars and proteins are vital for proper growth and development of the insect we explored the impact of EOs on these metabolites in $M$. domestica. The $\mathrm{LC}_{50}$ concentrations of EOs showed a notable influence on total body sugar, glycogen, lipid and protein content of third instar larvae. Comparably the LGEO exhibited high influence (reduction) over the total sugar, glycogen, and protein contents, whereas TTEO showed a significant effect on total lipid content in $M$. domestica larvae. The LGEO drastically reduced the total sugar, glycogen and protein contents by 3.29, 2.95 and 7.56 fold, respectively, while TTEO reduced the lipid content of larvae by 1.62 fold after treatment at $\mathrm{LC}_{50}$ concentration for $24 \mathrm{~h}$ (Fig. 5). Our inferences were consistent with the observations of Senthilkumar and his colleagues, [22] who reported a decrease in the concentration of proteins, lipids and carbohydrates by EOs. However, the reduction of glycogen and sugar content after treatment could be due to their involvement to combat the chemical stress imposed by the tested compounds. Hence, treatment with EOs might have possibly interrupted the metabolic processes and resulted in larval mortality [7]. The reduction of protein content by exposure to plant extracts is frequently reported in the literature. According to Shakoori and Saleem, [23] reduced level of proteins after treatment with EOs may be due to the breakdown of proteins into their amino acids, which help the insect for survival. Similarly, the reduced amount of sugar content in treated larvae of $M$. domestica could have occurred due to over exploitation of carbohydrate resources under stress conditions for proper maintenance of physiological metabolism. However, Khosravi et al. [24] stated that in G. pyloalis, sugar content is used to meet energy expenses for detoxification of $A$. аппиа extract which ultimately leads to exploitation of lipid contents of the body. Our results were in close agreement with the conclusions of Canavoso et al. [25] who detected reduction of lipids in the larvae of $S$. littoralis after treatment with lemon and garlic essential oils. The overall reduction in biochemical contents of the larvae due to EO treatment results in poor metabolism consequently leading to deformities or making the individuals prone to opportunistic diseases by pathogens as compared to normal larvae. Therefore, from the inferences of this test it can be concluded that tested EOs possess remarkable bioefficacy against nuisance causing pest i.e., house fly.

\section{Effect of EOs on Gut Enzymes of M. domestica}

The gut enzymes are key players for digestive physiology and health of all animals. Since house flies commonly dwell on sugary foods, their digestion mostly depends on amylases and glucosidases. Therefore, we determined the effect of EO on amylase and glucosidase activities in house fly larvae. Since some EOs are known to alter the digestive physiology of the insects, we investigated the effect of tested compounds on house fly larvae. However, we observed a significant difference in amylase activity between control and treated sets. The $\alpha$-amylase activity was drastically reduced from 0.21 to $0.074 \pm 0.001 \mathrm{U} / \mathrm{mg}$ protein and $0.1064 \pm 0.004 \mathrm{U} / \mathrm{mg}$ protein (Fig. 6). Similarly, a considerable reduction of $\alpha$ - and $\beta$-glucosidase activities were observed after treatment with EOs. In $\alpha$ glucosidase activity, LGEO proved to be more effective with a reasonable reduction from $2.45 \mathrm{U} / \mathrm{mg}$ of protein to $1.95 \pm 0.03 \mathrm{U} / \mathrm{mg}$ of protein followed by TTEO ( $2.37 \pm 0.07 \mathrm{U} / \mathrm{mg}$ of protein). However, in $\beta$-glucosidase activity, LG showed a higher effect, better than TTEO. The $\beta$-glucosidase activity was decreased from $3.06 \pm 0.07$ $\mathrm{U} / \mathrm{mg}$ of protein in control larvae to $2.65 \pm 0.04 \mathrm{U} / \mathrm{mg}$ of protein by $\mathrm{LG}$ and $2.75 \pm 0.02 \mathrm{U} / \mathrm{mg}$ of protein with TTEO. According to Mehrabadi et al. [26], if the action of the amylases is inhibited, it causes energy shortness, and ultimately death of the organism which supports our observations of larvicidal bioassay. The inhibition of $\alpha$ amylase activity in the treated larvae could be a cytotoxic effect on epithelial cells of the insect midgut which synthesizes it. Further, the authors suggested that treatment

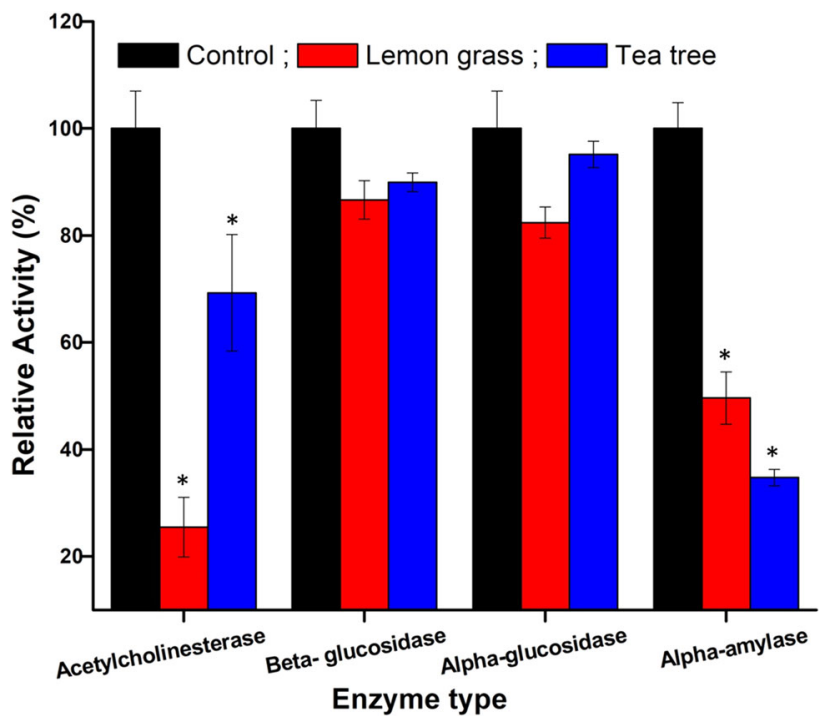

Fig. 6 Effect of essential oil treatment on the activity of gut enzymes and acetylcholinesterase in $M$. domestica. Data analyzed by One-way ANOVA, followed by Tukey's test and significance at $* p<0.001$ compared with control 
with EO causes lysis of cell wall, damages cytoplasm and affects lipid and protein contents [27]. However, in the case of $\alpha$ - and $\beta$-glucosidase activities, our finding was consistent with previous reports where $H$. rury larvae treated with sub lethal concentrations of biopesticides showed reduction of $\alpha$ - and $\beta$-glucosidase activities.

\section{Acetylcholinesterase (AChE) Activity}

The neurotransmitter AChE is pivotal for insects and higher animals. It plays a prominent role in cholinergic synapse in insects. The AChE elucidates the neurogenic toxicity of chemicals on insects, and in this study, it was observed that tested EOs displayed significant effect on acetylcholinesterase activity. Among the compounds, LGEO affected the neurotransmission by the inhibition of AChE activity to a greater extent $(0.00288 \pm 0.0002 \mathrm{U} / \mathrm{mg}$ of Protein) followed by tea tree $(0.00785 \pm 0.0005 \mathrm{U} / \mathrm{mg}$ of Protein) as compared to normal larvae $(0.01134 \pm 0.0003 \mathrm{U} / \mathrm{mg}$ of protein). The inhibition of $\mathrm{AChE}$ is largely imparted by the presence of monoterpenes present in aromatic compounds like EOs [27]. These results are in line with our previous observations [7] where EO from Laurus nobilis showed higher inhibitory activity of AChE in M. domestica. There are several reports concluding that monoterpenoids and many plant volatiles cause insect mortality by inhibiting acetylcholinesterase enzyme [28].

\section{GC-MS Analysis of EOs}

Plants serve as a reservoir for many active compounds with distinguished properties which attributes to their commercial value. The EOs extracted from plants with characteristic aroma are composites of oxygenated terpenes, hydrocarbons and sesquiterpenes, which impart special economical significance to these secondary metabolites. Since EOs differ in their chemical composition therefore, characterization becomes an important process to decipher their different chemotypes. The GC-MS is an ideal technique for the qualitative and quantitative determination of volatile and semi-volatile organic compounds in EOs. These components in EO are frequently identified by comparison of their unique retention indices and characteristic mass spectra.

The GC-MS analysis of the LGEO revealed 12 major compounds which show the highest mass spectra ratios (Fig. S1). The major components present in the oil were Citral (37.48\%) followed by Geranyl methanoate $(26.88 \%)$, acetone $(10.66 \%)$ and cyclobutane $(4.58 \%)$ (Table S1). In case of TTEO, we observed 5 major compounds such as Terpinen-4-ol $(45.78 \%)>\gamma$-terpinene $(16.52 \%),>4$-carene $(8.75 \%),>\beta$-Cymene $(7.98 \%)$ followed by the least proportion of $\alpha$-Terpineol $(4.48 \%)$. Lemongrass is generally known to contain citral as a major component which is a complex of bioactive isomers like neral and geranial. Huynh, [29] reported that citral also known as 3,7-dimethyl-2, 6-octadienal is a natural mixture of isomeric acyclic monoterpene aldehydes, i.e., geranial (transcitral, citral A) and neral (cis-citral, citral B). However, earlier researchers [30] have stated that TTEO contains 3 major constituents such as 4-terpineol, $\gamma$-terpinene and $\alpha$ - terpinene, the distribution and abundance of these constituents in EOs depends on many factors such as genetic variations and geographical conditions of the plant species.

\section{Field Emission Scanning Electron Microscopic (FESEM) Analysis}

To have a clear visualization of the morphological alterations induced by EO treatment to the house fly larvae, the FESEM analysis evaluated the ultra-structural changes in the larval integument. The marked changes caused by EO treatment are shrinkage of body segments, along with withered anterior segments (Fig. 7). However, in case of control set where larvae were treated with acetone only, the body appearance was clear and smooth without any distorted structure. Like LG, the TTEO was also found to cause shrinkage and distortion of the larval body. Recently, Kumar et al. [10] also reported similar effects on surface morphology of $M$. domestica larvae due to treatment of $E$. globules EO. They further elucidated that E. globulus oil causes surface shrinkage at spinose rings with protruding intersegmental grooves. The surface aberration on insect larva could be caused due to absorption of plant extracts to the larval gut or by ingestion through the cuticle and gut epithelial cells. Similarly, Kumar et al. [10] also observed an effect on proliferation of spinose cells after treatment with EO. According to Pérez-Serrano et al. [30] loss of integument organization is a result of stress responses to EO toxicity.

During the last few decades, numerous studies have tested the efficacy of plant-based formulations against mosquitoes which is largely lacking in case of house flies. Taking into consideration, we determined the effect of LG and TTEOs on different forms of M. domestica. As evident from the observations, LG and TT oils showed potential bioefficacy against different life stages of the housefly. Since LG and TTEOs significantly reduced the metabolic contents and inhibited the enzymes like AChE, $\alpha$-amylase, etc. the present study signposts the insecticidal repertoire of tested compounds for the sustainable management of houseflies. The inhibition of pupal emergence into adults together with larvicidal and adulticidal effects also suggest the formulation of these botanicals for potential industrial 


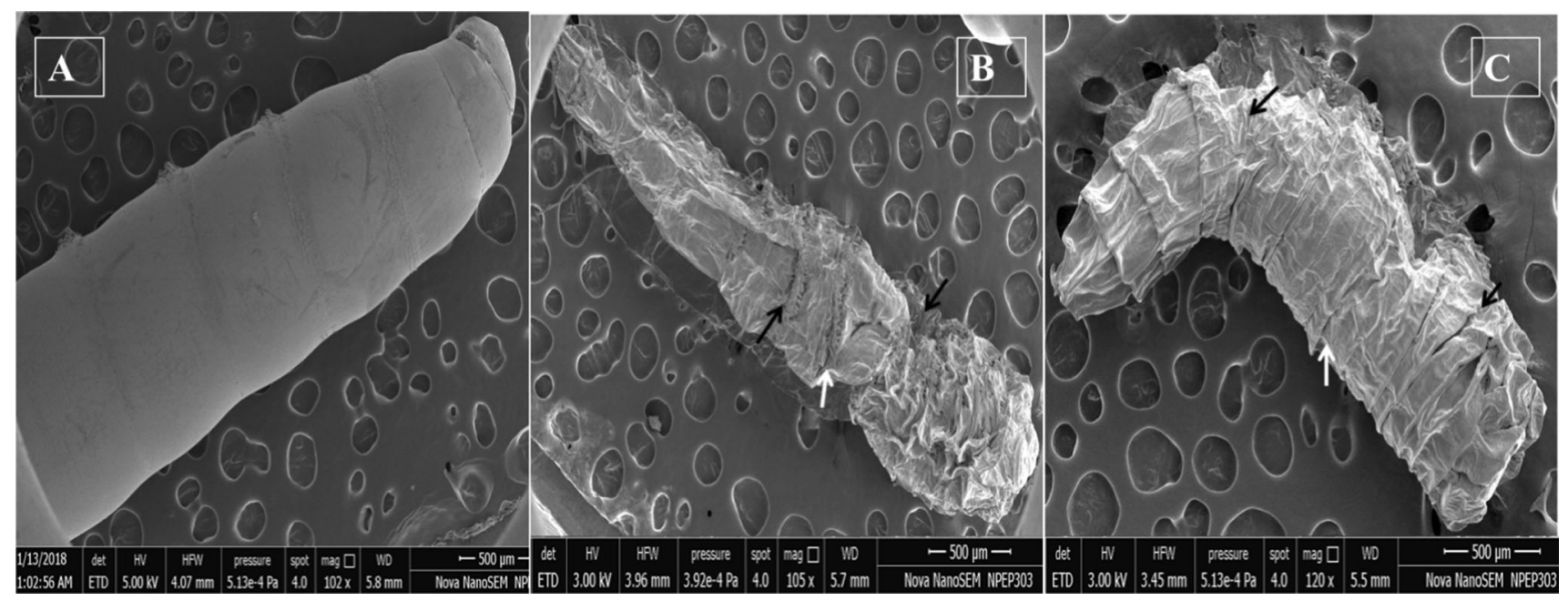

Fig. 7 The ultra-structural view of the alterations cause by essential oil treatment to the surface of housefly larvae for $24 \mathrm{~h}$. Scanning electron microscopic a; smooth and normal morphology of the control larvae, $\mathbf{b}$; morphometric shrinkage of the larval integument caused by

applications. The tested oils can thus be easily formulated as microemulsions or nanoemulsions in water or ecofriendly solvent systems. The microemulsions are known to enhance bioefficacy and provide long-term stability to the botanicals. Being volatile, the EOs can also be dissolved in solvents and kept at desired places inside buildings whereby they function as strong repellents for houseflies. In conclusion, LG and TTEOs could prove as important candidates for pest control strategy against houseflies due to their intrinsic larvicidal, pupicidal and adulticidal properties while LG may also act as an effective repellent and ovipositional deterrent for closely related species. However, for field trials and formulation of tested EOs a comprehensive understanding of their mechanism of action on model insect becomes imperative to avert the effects on non-target fauna. Therefore, our future perspective will be to characterize the transcriptome of $M$. domestica in response to EO treatment to better understand the mechanisms associated with their insecticidal activities.

\section{Conclusion}

To determine the insecticidal potential of EOs from LG and TT against $M$. domestica different experiments were carried out on different stages of the model insect. In most of the experiments, tested compounds showed significant effects for the control of $M$. domestica. In adulticidal and repellency assays, TTEO proved more effective than LGEO. In contrast, LGEO showed more potential as fumigant for $(14.49 \mu \mathrm{L} / 0.25 \mathrm{~L}$ of air) pupae of house fly. The present study concludes the significant efficacy of EOs treatment with lemongrass EO, c; morphometric shrinkage and rupturing of body contents caused by treatment with tea tree EO. Arrows indicate the marked changes caused by the treatment of essential oils

under consideration against $M$. domestica which could be employed to breakdown its population below threshold levels to prevent the menace of some vector-borne diseases. The treatment of TTEO significantly decreased sugar, glycogen and lipid contents whereas LGEO highly affects the total protein content of $M$. domestica. A considerable reduction of $\alpha$ - and $\beta$-glucosidase activities was found in treated larvae as compared to the control. The above all findings of the present study brands TT and LGEOs as potential agents for eco-friendly management of houseflies under IPM program encouraging field trials.

Acknowledgements JMC is highly indebted to S. P. Pune University, Pune for providing research stipend and infrastructural support necessary to carry out the presented work. MD acknowledges University Grants Commission (UGC), New Delhi, India, for senior research fellowship. The grants sanctioned under UGC-CAS phase 3, DRDP and DST-PURSE schemes to RSP are also acknowledged.

\section{Compliance with Ethical Standards}

Conflict of interest The authors declare that they have no conflict of interest.

\section{References}

1. Wanaratana S, Amonsin A, Chaisingh A, Panyim S, Sasipreeyajan J, Pakpinyo S (2013) Experimental assessment of houseflies as vectors in avian influenza subtype H5N1 transmission in chickens. Avian Dis 57:266-272. https://doi.org/10.16 37/10347-090412-Reg.1

2. Lietze VU, Sims KR, Salem TZ, Geden CJ, Bouciasa DG (2009) Transmission of MdSGHV among adult house flies, Musca domestica (Diptera: Muscidae), occurs via oral secretions and 
excreta. J Invertebr Pathol 101:49-55. https://doi.org/10.101 6/j.jip.2009.02.007

3. Geden C (2012) Status of biopesticides for control of house flies. JBiopest 5:1-11

4. Isman MB (2006) Botanical insecticides, deterrents and repellents in modern agriculture and an increasingly regulated world. Annu Rev Entomol 51:45-66. https://doi.org/10.1146/annu rev.ento.51.110104.151146

5. Cavalca PAM, Lolis MIGA, Reis B, Bonato CM (2010) Homeopathic and larvicide effect of Eucalyptus cinerea essential oil against Aedes aegypti. Braz Arch Biol Tech 53:835-843. https://doi.org/10.1590/S1516-89132010000400012

6. Souza TM, Cunha AP, Farias DF, Machado LK, Morais SM, Ricardo NMPS, Carvalho AFU (2012) Insecticidal activity against Aedes aegypti of m-pentadecadienyl-phenol isolated from Myracrodruon urundeuva seeds. Pest Manag Sci. https://doi.org/10.1002/ps.3316

7. Chintalchere JM, Dar MA, Pandit RS (2020) Biocontrol efficacy of bay essential oil against housefly, Musca domestica (Diptera: Muscidae). J Basic Appl Zool 81:6. https://doi.org/10.1186/s41 936-020-0138-7

8. Sanchez-Arroyo, H., Capinera, J.L., 1998. House fly, Musca domestica Linnaeus (Insecta: Diptera: Muscidae). UF/IFAS Extension, University of Florida, EENY-048. http://entnemdept.if as.ufl.edu/creatures/

9. Finney D (1992) Probit analysis, vol 2. Cambridge University Press, Cambridge

10. Kumar P, Mishra S, Malik A, Satya S (2012) Compositional analysis and insecticidal activity of Eucalyptus globulus (family: Myrtaceae) essential oil against housefly (Musca domestica). Acta Trop 122:212-218. https://doi.org/10.1016/j.actatropi ca.2012.01.015

11. Van-Handel E, Day JF (1988) Assay of lipids, glycogen and sugars in individual mosquitoes: correlations with wing length in field-collected Aedes vexans. J Am Mosq Control Assoc 4:549-550 PMID: 3225576

12. Bradford MM (1976) A rapid and sensitive method for the quantitation of microgram quantities of protein utilizing the principle of dye binding. Anal Biochem 72:248-254. https://doi.org/10.1016/0003-2697(76)90527-3

13. Miller GL (1959) Use of dinitrosalicylic acid reagent for determination of reducing sugar. Anal Chem 31:426-428. https://doi.org/10.1021/ac60147a030

14. Ellman GL, Courtney KD, Andres V, Featherstone RM (1961) A new and rapid colorimetric determination of acetylcholinesterase activity. Biochem Pharmacol 7:88-95. https://doi.org/10.101 6/0006-2952(61)90145-9

15. Mirghani MES, Liyana Y, Parveen J (2012) Bioactivity analysis of lemongrass (Cymbopogan citratus) essential oil. Int Food Res J 19:569-575

16. Shalaby AA, Allam KA, Mostafa AA, Fahmy SM (1998) Insecticidal properties of citrus oils against Culex pipiens and Musca domestica. J Egypt Soc Parasitol 28:595-606

17. Bosly AH (2013) Evaluation of insecticidal activities of Mentha piperita and Lavandula angustifolia essential oils against housefly, Musca domestica L. J Entomol Nematol 5:50-54. https://doi.org/10.5897/JEN2013.0073
18. Oyedele AO, Gbolade AA, Sosan MB, Adewoyin FB, Soyelu OL, Orafidiya LO (2002) Formulation of an effective mosquitorepellent topical product from lemongrass oil. Phytomedicine 9:259-262. https://doi.org/10.1078/0944-7113-00120

19. Jayasinghe ULB, Fujimoto Y (1999) Insecticidal saponin from Pometia eximia. Fitoterapia 70:87-88. https://doi.org/10.1016/S 0367-326X(98)00008-2

20. Dimetry NZ, Hafez M, Abbas MH (2003) Efficiency of some oils and neem formuations against the cow peabeetle, Callosobrochus maculatus (Fabricius) (Coleoptera: Bruchidae). Biopestic Pest Manag 2:1-10

21. Ezeonu FC, Chidume GI, Udedi SC (2001) Insecticidal properties of volatile extracts of orange peels. Biores Technol 76:273-274. https://doi.org/10.1016/S0960-8524(00)00120-6

22. Senthilkumar N, Varma P, Gurusubramanian G (2009) Larvicidal and adulticidal activities of some medicinal plants against the malarial vector, Anopheles stephensi (Liston). Parasitol Res 104:237-244. https://doi.org/10.1007/s00436-008-1180-4

23. Shakoori AR, Saleem MA (1989) Some macromolecular abnormalities developed by the interaction of malathion and permethrin and subsequent re feeding in Tribolium castaneum larvae. Arch. Ins. Biochem. Physiol. 11:203-215. https://doi.org/10.10 02/arch.940110402

24. Khosravi R, Sendi JJ, Ghadamyari M, Yazdani E (2011) Effect of sweet wormwood Artemisia апnиа crude leaf extracts on some biological and physiological characteristics of the lesser mulberry pyralid, Glyphodes pyloalis. J Insect Sci. https://doi.org/10.10 16/j.aspen.2013.07.002

25. Canavoso LE, Jouni ZE, Karnas KJ, Pennington JE, Wells MA (2001) Fat metabolism in insects. Annu Rev Nutr 21:23-46. https://doi.org/10.1146/annurev.nutr.21.1.23

26. Mehrabadi M, Bandani AR, Saadati F (2010) Inhibition of Sunn pest, Eurygaster integriceps, $\alpha$-amylases by $\alpha$-amylase inhibitors ( $\mathrm{T}-\alpha$ AI) from Triticale. J Insect Sci. https://doi.org/10.167 3/031.010.14139

27. Lopez MD, Pascual Villalobos MJ (2010) Mode of inhibition of acetylcholinesterase by monoterpenoids and implications for pest control. Ind Crop Prod 31:284-288. https://doi.org/10.1016/ j.indcrop.2009.11.005

28. Huynh KPH, Maridable J, Gaspillo P, Hasika M, Malaluan R, Kawasaki J (2008) Essential oil from lemongrass extracted by supercritical carbon dioxide and steam distillation. Philippine Agric. Sci. 91:36-41

29. Shellie R, Marriott P, Cornwell C (2001) Application of comprehensive two-dimensional gas chromatography $(\mathrm{GC} \times \mathrm{GC})$ to the enantio selective analysis of essential oils. J Sep Sci 24:823-830. https://doi.org/10.1002/1615-9314(20011101) $24: 10 / 113.0 . \mathrm{CO} ; 2-\mathrm{H}$

30. Pérez-Serrano J, Casado N, Denegri G, Rogriguez-Caabeiro F (1994) The effects of albendazole and albendazole sulphoxide combination therapy on Echinococcus granulosus in vitro. Int $\mathbf{J}$ Parasitol 24:219-224. https://doi.org/10.1016/0020-7519(94)90 029-9

Publisher's Note Springer Nature remains neutral with regard to jurisdictional claims in published maps and institutional affiliations. 